\title{
Análise do albedo da superfície e de índices de vegetação por sensoriamento remoto na bacia hidrográfica do Rio Pacoti/CE
}

\author{
Analysis of surface albedo and vegetation areas from orbital images \\ in the Pacoti / CE river basin
}

Análisis del albedo de la superficie e índice de vegetación por
sensoriamento remoto en la cuenca hidrográfica del rio Pacoti/CE

Analyse de l'albédo de la surface et des indices de végétation par télédétection chez la bassin de la rivière Pacoti/EC

José Jeová Ferreira

Júnior (OrcID)

Junior-ferreir@edu.unifor. br

Universidade de Fortaleza - Unifor

Maria Jorgiana Ferreira Dantas (OrcID) jorgiana@unifor.br Universidade de Fortaleza - Unifor

\begin{abstract}
Resumo
O albedo é a razão entre a radiância refletida e a incidente da superfície, sendo um importante índice utilizado na climatologia e em outras ciências atmosféricas, assim como o Índice de Vegetação Por Diferença Normalizada (Normalized Difference Vegetation Index - NDVI) e o Índice de Vegetação Ajustada ao Solo (Soil Adjusted Vegetation Index - SAVI), que proporcionam a identificação da presença de vegetação verde na superfície e a caracterização de sua distribuição espacial; e juntas são ferramentas importantes para o reconhecimento de processos de degradação. Esses índices podem ser gerados pela relação entre as bandas do espectro eletromagnético, sendo utilizados para a obtenção de informações relevantes conseguidas através de sensores de satélites Landsat 5 e 8 , em relação à vegetação presente na área estudada. A metodologia constitui-se no levantamento bibliográfico para a fundamentação do estudo, com a finalidade de compreender os aspectos ambientais mediante as atividades antrópicas. Destacou-se o uso do software ArcGIS 10.3 através da álgebra de mapas, sendo necessário para obter uma análise ambiental. Os resultados de albedo da superfície e dos índices de vegetação foram satisfatórios, corroborando com vários autores e conseguindo demonstrar a degradação sofrida na região, como o aumento das culturas, a diminuição da área vegetada e o aumento do solo exposto. De maneira geral, pode-se concluir que, de acordo com os resultados, o uso das técnicas de sensoriamento remoto, sistema de informações geográficas e geoprocessamento, associadas às imagens Landsat, podem ser usadas com um alto grau de confiabilidade na determinação do albedo e de índices de vegetação.
\end{abstract}

Palavras-chave: Albedo. NDVI. SAVI. Sensoriamento remoto.

\begin{abstract}
Albedo is the ratio between reflected and incident radiance of the surface, being an important index used in climatology and other atmospheric sciences, as well as the Normalized Difference Vegetation Index (NDVI) and the Soil Adjusted Vegetation Index (SAVI) which provide the identification of the presence of green vegetation on the surface and the characterization of its spatial distribution, together are important tools for the recognition of degradation processes. These indices can be generated by the relation between the bands of the electromagnetic spectrum, being used to obtain relevant information obtained by the satellite sensors Landsat 5 and 8 in relation to the vegetation present in the studied area. The methodology is the bibliographical survey for the foundation of the study, with the purpose of understanding the environmental aspects through the anthropic activities; we highlighted the use of ArcGIS 10.3 software, through map algebra, necessary to obtain an environmental analysis. The results of surface albedo and vegetation indexes were satisfactory, corroborating with several authors, demonstrating the degradation suffered in the region, such as the increase of crops, decrease of vegetation area and increase of exposed soil. In general, it can be concluded that according to the results, the use of the remote sensing, geographic information system and geoprocessing techniques, associated with Landsat images, can be used with a high degree of reliability in albedo determination and indices of vegetation.
\end{abstract}

Keywords: Albedo. NDVI. SAVI. Remote sensing. 


\title{
Resumen
}

El albedo es la división entre la radiación reflejada y la incidente de la superficie, siendo un importante índice utilizado en la climatología y en otras ciencias atmosféricas, así como el Índice de Vegetación por Diferencia normalizada (NDVI) y el Índice de Vegetación Ajustada al suelo (SAVI) que proporcionan la identificación de la presencia de vegetación verde en la superficie y la caracterización de su reparto espacial, juntas son herramientas importantes para el reconocimiento de procesos de degradación. Estos índices pueden ser generados por la relación entre las bandas del espectro electromagnético, siendo utilizadas para la obtención de informaciones relevantes logradas por sensores de satélites Landsat 5 y 8 en relación con la vegetación presente en el área investigada. La metodología está basada en la búsqueda bibliográfica para fundamentación del estudio, con el objetivo de comprender los aspectos ambientales ante las actividades antrópicas; resaltamos el uso del software ArcGIS 10.3, por medio del álgebra de mapas, necesario para obtener un análisis ambiental. Los resultados del albedo de la superficie y de los índices de vegetación fueron satisfactorios corroborando con diversos autores, logrando demostrar la degradación sufrida en la región, como el incremento de las culturas, disminución del área vegetada e incremento del suelo expuesto. De modo general se puede concluir que, de acuerdo con los resultados, el uso de técnicas de sensoriamento remoto, sistema de informaciones geográficas y geo procesamiento, asociadas a las imágenes Landsat, pueden ser usadas con un alto grado de fiabilidad en la determinación del albedo e índice de vegetación.

Palabras-clave: Albedo. NDVI. SAVI. Sensoriamento remoto.

\begin{abstract}
Résumé
L'albédo est le rapport entre le rayonnement reflété et incident de la surface, il s'agit d'un indice important utilisé chez la climatologie et autres sciences de l'atmosphère, tel comme l'Indice de Végétation par Différence Normalisée (NDVI) et l'Indice de Végétation Ajustée au Sol (SAVI). Ce sont eux qui fournissent l'identification de la présence de végétation verte sur la surface et la caractérisation de sa distribution spatiale. Ensemble, ils sont des outils importants pour la reconnaissance des processus de dégradation. Ces indices peuvent être générés par la relation entre les bandes du spectre électromagnétique, utilisées pour obtenir des renseignements pertinents obtenus par les capteurs du satellite Landsat 5 et 8 par rapport à la végétation présente dans la zone étudiée. La méthodologie s'agit-elle de l'enquête bibliographique pour fondamenter de l'étude, dans le but de comprendre les aspects environnementaux devant des activités anthropiques; on peut mettre en relief l'utilisation du logiciel ArcGIS 10.3, par l'algèbre de carte, nécessaire pour obtenir une analyse environnementale. Les résultats de l'albédo de la surface et des indices de végétations ont été satisfaisants, ce qui corrobore avec plusieurs auteurs, et réussi à démontrer la dégradation dans la région, tels que l'augmentation des cultures, diminution de la zone végétative et augmentation du sol exposé. En général, on peut donc conclure que, selon les résultats, l'utilisation de techniques de télédétection, de systèmes d'information géographique et de géotraitement, associées avec les images de Landsat, peuvent être utilisées avec un degré élevé de fiabilité dans la détermination des indices de l'albédo et de végétation.
\end{abstract}

Mot-Clés: Albédo. NDVI. SAVI. La télédétection.

\section{Introdução}

Com o grande desenvolvimento tecnológico, o uso de novas plataformas aéreas, como os satélites, tornou-se uma das principais ferramentas para análise e estudos avançados sobre a superfície terrestre, os quais são importantes para a deteç̧ão e monitoramento de mudanças, proporcionando uma melhor avaliação, manejo e gerenciamento dos recursos naturais, como o solo e a vegetação. Deste modo, é possível identificar as principais causas de degradação dos recursos naturais, que, em sua maioria, são ocasionados por ações antrópicas, tais como: queimadas, desmatamento, uso e ocupação do solo, atividades agrícolas e de pecuária; constantemente sendo provocadas por populações com baixo ou nenhum senso crítico ambiental, impactando diretamente as bacias hidrográficas, no contexto do clima semiárido nordestino, são bastante importantes para o equilíbrio natural do ambiente, que sofre com secas periódicas.

Assim, estudos nesta área tornam-se necessários, a fim de compreender as inter-relações existentes entre os fatores e os processos hidrológicos de uma bacia, que pode ser definida como uma área de captação natural da precipitação, convergindose em escoamentos até formar um comportamento ou ciclo hidrológico (TUCCI, 2006). Segundo Bandeira et al. (2017), estudar as bacias hidrográficas em um contexto semiárido é importante para um equilíbrio natural do ambiente, sobretudo em razão dos seus múltiplos usos: ocupação urbana, turismo e lazer, uso dos recursos hídricos, agricultura e pecuária. 
O objeto do presente trabalho é analisar a bacia do Rio Pacoti/CE, inserida em uma região de estresse hídrico, causado pelas secas frequentes e chuvas periódicas. Dessa maneira, faz-se necessário um manejo ambiental adequado, encaixando-se no desenvolvimento sustentável e, consequentemente, precisa haver uma abordagem do gerenciamento ambiental de maneira multidisciplinar.

O sensoriamento remoto é uma ferramenta que se torna fundamental no manejo de bacias, ajudando na identificação e monitoramento de possíveis mudanças nos recursos naturais. Segundo Menezes e Almeida (2012), teve origem nos anos 60 e, desde então, tornou-se uma técnica importante na obtenção de tais resultados.

O Sistema de Informação Geográfica - SIG é outra importante ferramenta para análises ambientais em escala de bacias hidrográficas, usada para investigar regiões vulneráveis (DANTAS et al., 2017), sendo uma ferramenta de geoprocessamento que permite o armazenamento, a recuperação, a manipulação e a análise espacial de dados, com aplicação em diferentes áreas de estudo.

Com isso, alguns parâmetros, como o albedo, os índices de vegetação e da situação hídrica regional, são considerados importantes para o conhecimento e acompanhamento de recursos naturais, principalmente em países como o Brasil, por possuir dimensões continentais, sendo a técnica do sensoriamento remoto uma alternativa (IDEÃO, 2009).

Em vista disso, o albedo pode ser definido como a parte da radiação incidente na superfície, refletida devido ao coeficiente de reflexão, fator específico ao tipo de superfície refletida (SILVA, 2014) e, associado ao NDVI e ao SAVI, são obtidas informações sobre a quantidade de biomassa verde e de parâmetros de desenvolvimento e crescimento da vegetação (DANTAS et al., 2017).

Nesse contexto, o objetivo deste trabalho é analisar o albedo da superfície e os índices de vegetação na bacia hidrográfica do Rio Pacoti/CE, por meio de imagens orbitais. Desta forma, as páginas a seguir são pertinentes por conseguir retratar, através de imagens e mapas, a degradação sofrida, principalmente por ações antrópicas na bacia hidrográfica citada.

A escolha pelo sensoriamento remoto é importante, porque, com o uso dessa técnica, é possível fazer o gerenciamento ambiental de grandes áreas sem a necessidade de visitação ou até mesmo sem limitações de espaço, sendo escolhida a bacia hidrográfica do Rio Pacoti/CE por sua importância no cenário de abastecimento da Região Metropolitana de Fortaleza RMF e por ser considerada uma bacia de extrema relevância devido ao seu potencial hídrico.

\section{Metodologia}

A metodologia tem por natureza uma pesquisa aplicada, com abordagem quali/quantitativa, constituindo-se de levantamento bibliográfico realizado a partir de artigos científicos, teses e livros para fundamentação da pesquisa. A área de estudo é a bacia hidrográfica do Pacoti, que está inserida na bacia hidrográfica metropolitana, no estado do Ceará, que se divide em 12 regiões hidrográficas: Bacias do Alto Jaguaribe, Bacia do Acaraú, Bacia do Baixo Jaguaribe, Bacia do Coreaú, Bacia do Curu, Bacia do Litoral, Bacia do Médio Jaguaribe, Bacia Metropolitana, Bacia dos Sertões de Crateús, Bacia do Salgado, Bacia do Banabuiú e Bacia da Serra da Ibiapaba.

Assim, a área de estudo compreende a bacia hidrográfica do Rio Pacoti/CE, que se situa na zona semiárida do Nordeste Brasileiro e possui uma área total de $717,06 \mathrm{~km}^{2}$, dispondo cerca de $4 \mathrm{~km}^{2}$ de área inserida no município de Fortaleza, sendo a principal bacia metropolitana e uma das mais importantes em todo o estado do Ceará. O rio homônimo tem um curso de cerca de $112,5 \mathrm{~km}$, com uma área de aproximadamente $1.257 \mathrm{~km}^{2}$, e suas nascentes estão localizadas na vertente setentrional do Maciço de Baturité, a um nível altimétrico de $700 \mathrm{~m}$ a $900 \mathrm{~m}$, integrando os municípios de Pacoti e Guaramiranga, com Latitude de S $4^{\circ} 12^{\prime}$ e Longitude de W $38^{\circ} 54^{\prime}$, estando a sua foz localizada no município de Aquiraz. Na faixa costeira, o rio passa pelos seguintes municípios: Pacoti, Redenção, Acarape, Pacajus, Guaiúba, Horizonte, Itaitinga, Fortaleza, Eusébio e Aquiraz (QUEIROZ, 2010).

Uma das características mais significativas de regiões semiáridas é o fato da presença de dois períodos climáticos predominantes: chuvoso e seco. O município de Pacoti apresenta os meses de janeiro a maio com o período chuvoso e uma pluviosidade média anual de 1.558,1 mm, não apresentando grande potencial hídrico. Porém, em épocas de seca, tem papel importante no abastecimento da região metropolitana pela bacia hidrográfica do Pacoti (IPECE, 2016).

Foram utilizadas imagens obtidas dos satélites Landsat 5 e também do Landsat 8. A princípio, todas as bandas do TM e OLI/TIRS foram empilhadas, recortadas e registradas antes de se obter os parâmetros de albedo, NDVI e SAVI. Depois, foram selecionadas imagens geradas pelo mapeador temático - TM do satélite Landsat 5, órbita 217 e ponto 63, adquiridas 
junto ao site do Instituto de Pesquisas Espaciais - INPE. Cada imagem contém sete bandas espectrais, tendo as principais características representadas na tabela 1 , que mostra os dados empregados na conversão da refletância monocromática em albedo e algumas características das bandas espectrais. Essas imagens são referentes à passagem do Landsat 5, às $9 \mathrm{~h} 30$ (tempo local), em 14/07/2016 e em 03/09/2017. O sensor TM tem a capacidade de medir a radiância espectral dos pontos e armazená-los na forma de níveis de cinza, ou número digital (ND), cujos valores variam de 0 a 225 (8 bits), mostrando uma resolução espacial de 30 metros, exceto para a banda 6 (banda termal), com uma resolução de 120 metros.

Tabela 1 - Coeficientes de calibração do TM - Landsat 5 ab e bb, irradiância solar espectral de cada banda no topo da atmosfera $-\mathrm{kb}$.

\begin{tabular}{|c|c|c|c|c|c|}
\hline \multirow[t]{2}{*}{ Bandas } & \multirow{2}{*}{$\begin{array}{c}\text { Comprimento } \\
\text { de Onda } \\
(\mu \mathrm{m})\end{array}$} & \multirow[t]{2}{*}{$\begin{array}{l}\text { Resolução } \\
\text { (m) }\end{array}$} & \multicolumn{2}{|c|}{$\begin{array}{c}\text { Coeficientes de calibração } \\
\left(\mathbf{W m}^{\sim 2} \mathbf{s} \mathbf{r}^{-1} \mu^{\sim 1}\right)\end{array}$} & \multirow{2}{*}{$\begin{array}{c}\text { Irradiância Espectral nc } \\
\text { Topo da Atmosfera } \\
\left(\mathbf{W m}^{\sim 2} \mu \mathrm{m}^{\sim 1}\right)\end{array}$} \\
\hline & & & $\mathrm{a}$ & $\mathrm{b}$ & \\
\hline 1 (azul) & $0,45-0,52$ & 30 & $-1,52$ & 193,0 & 1957 \\
\hline 2 (verde) & $0,52-0,60$ & 30 & $-2,84$ & 365,0 & 1826 \\
\hline 3 (vermelho) & $0,63-0,69$ & 30 & $-1,17$ & 264,0 & 1554 \\
\hline 4 (IV - próximo) & $0,76-0,79$ & 30 & $-1,51$ & 221,0 & 1036 \\
\hline 5 (IV - médio) & $1,55-1,75$ & 30 & $-0,37$ & 30,2 & 215 \\
\hline 6 (IV - termal) & $10,4-12,5$ & 120 & 1,23 & 15,3 & - \\
\hline 7 (IV - médio) & $2,08-2,35$ & 30 & $-0,15$ & 16,5 & 80,67 \\
\hline
\end{tabular}

Fonte: Chander e Markhan (2003) e Allen et al. (2002).

Também foram empregadas imagens geradas pelo Operational Land Imager - OLI e Thermal Infrared Sensor - TIRS do satélite Landsat 8, com órbita 217 e ponto 63, adquirida junto ao USGS, correspondendo aos dias 08/08/2015, 26/08/2016 e 28/09/2017. Cada imagem OLI é composta por nove bandas, tendo suas características principais apresentadas na tabela 2, que mostra os dados empregados na conversão da refletância monocromática em albedo e algumas características das bandas espectrais. O TIRS possui duas bandas espectrais, as bandas $10 \mathrm{e} 11$. Essas imagens se referem à passagem do Landsat 8 , às $9 \mathrm{~h} 30$ (tempo local), nos respectivos anos, tendo a resolução espacial de 30 metros, exceto a banda pancromática, com 15 metros. Já as bandas 10 e 11, correspondentes ao sensor TIRS, têm resolução espectral de 12 bits, mas estão disponíveis em 16 bits, assegurando um maior nível de informações sobre as áreas das imagens.

Tabela 2 - Coeficientes de calibração do OLI - Landsat 8 ab e bb, irradiância solar espectral de cada banda no topo da atmosfera $-\mathrm{kb}$.

\begin{tabular}{|c|c|c|c|c|}
\hline \multirow[t]{2}{*}{ Bandas } & \multirow{2}{*}{$\begin{array}{c}\text { Comprimento de } \\
\text { Onda } \\
(\mu \mathrm{m})\end{array}$} & \multicolumn{2}{|c|}{$\begin{array}{c}\text { Coeficientes de calibração } \\
\left(W m^{\sim 2} \mathbf{s r}^{\sim 1} \mu^{-1}\right)\end{array}$} & \multirow{2}{*}{$\begin{array}{c}\text { Irradiância Espectral no } \\
\text { Topo da Atmosfera } \\
\left(\mathbf{W m}^{\sim 2} \mu \mathrm{m}^{\sim}\right)\end{array}$} \\
\hline & & $\mathrm{a}$ & $\mathrm{b}$ & \\
\hline $1 \mathrm{OLI}$ & $0,43-0,45$ & $-62,49131$ & 756,73364 & 1627,3 \\
\hline $2 \mathrm{OLI}$ & $0,45-0,51$ & $-63,72469$ & 771,66919 & 1812,5 \\
\hline $3 \mathrm{OLI}$ & $0,53-0,59$ & $-58,35032$ & 706,58862 & 1932,1 \\
\hline $4 \mathrm{OLI}$ & $0,64-0,67$ & $-49,41915$ & 598,43732 & 1579,9 \\
\hline $5 \mathrm{OLI}$ & $0,85-0,88$ & $-29,98809$ & 363,13843 & 905,3 \\
\hline $6 \mathrm{OLI}$ & $1,57-1,65$ & $-7,55550$ & 91,49276 & 242,6 \\
\hline $7 \mathrm{OLI}$ & $2,11-2,29$ & $-2,45779$ & 29,76242 & 56,0 \\
\hline $8 \mathrm{OLI}$ & $0,50-0,68$ & $-55,66755$ & 674,10181 & - \\
\hline 9 OLI & $1,36-1,38$ & $-12,32335$ & 149,22865 & - \\
\hline 10 TIRS & $10,60-11,19$ & 0,10033 & 22,00180 & - \\
\hline 11 TIRS & $11,50-12,51$ & 0,10033 & 22,00180 & - \\
\hline
\end{tabular}

Fonte: USGS (2013) e Silva (2014) 
As imagens obtidas através dos satélites Landsat 5 e 8 foram georreferenciadas no software ArcGIS 10.3, com o auxílio do programa Google Earth, a fim de localizar pontos de controle, que oferecem uma feição física identificável, tais como estradas, corpos hídricos e pontos de fácil reconhecimento, selecionando as coordenadas $\mathrm{X}$ e Y.

Por fim, foi analisado se o erro estava nos parâmetros cabíveis do georreferenciamento, tornando suas coordenas conhecidas no sistema SIRGAS 2000. Em seguida, as imagens foram empilhadas e recortadas nos laboratórios de informática da Universidade de Fortaleza - Unifor.

Após esses processos, foram aplicadas as fórmulas apresentadas adiante, utilizando a álgebra de mapas no software $\operatorname{ArcGIS} 10.3$, a fim de encontrar os valores necessários para as análises de albedo, NDVI e SAVI.

\section{Calibração radiométrica:}

Seguindo a proposta de Chander e Markhan (2003), apresenta-se o cálculo da radiância espectral das bandas $\mathrm{L}_{\lambda \mathrm{i}}$, no qual o número digital (ND) de cada pixel da imagem é convertido em radiância espectral monocromática, representando a energia solar refletida por unidade de área, de tempo, de ângulo sólido e de comprimento de onda, utilizando a equação 1:

$$
\iota_{\lambda i}=a_{i}+\frac{b_{1}-a_{1}}{355} \times N D L_{\lambda i}=a_{i}+\frac{b_{1}-a_{1}}{355} \times N D
$$

Em que: $\mathrm{L}_{\lambda_{1}}$ é a radiância espectral de cada banda $\left(\mathrm{W} \mathrm{m}^{-2} \mathrm{st}^{-1} \mathrm{~mm}^{-1}\right) ; \mathrm{a}_{\mathrm{i}}$ é o coeficiente de calibração (radiância mínima) de cada banda ( $\left.\mathrm{W} \mathrm{m}^{-2} \mathrm{st}^{-1} \mu \mathrm{m}^{-1}\right) ; \mathrm{b}_{\mathrm{i}}$ é o coeficiente de calibração (radiância máxima) de cada banda $\left(\mathrm{W} \mathrm{m}^{-2} \mathrm{st}^{-1} \mu \mathrm{m}^{-1}\right.$ ); i são as bandas do Landsat 5, e ND é o número digital de cada pixel na imagem.

\section{Reflectância:}

Segundo Allen et al, (2002), para o cálculo da reflectância monocromática de cada banda $\rho \lambda i$, sendo definida entre a razão do fluxo de radiação solar refletido e o fluxo de radiação global incidente, realiza-se a seguinte equação 2 :

$$
\rho_{\lambda i}=\frac{\pi \cdot L_{\lambda i}}{k_{\lambda i} \cdot \cos Z \cdot d_{r}} \rho_{\lambda i}=\frac{\pi \cdot L_{\lambda i}}{k_{\lambda i} \cdot \cos Z \cdot d_{r}}
$$

Em que: $\mathrm{L}_{\lambda \mathrm{i}, \mathrm{e}}$ a radiância espectral de cada banda; $\mathrm{k}_{\lambda_{\mathrm{i}}}$ é a irradiância solar espectral de cada banda no topo da atmosfera $\left(\mathrm{Wm}^{-2} \mu \mathrm{m}^{-1}\right) ; Z$ é o ângulo zenital solar (sendo obtido por meio do cabeçalho das imagens adquiridas, e depende da órbita/ponto e da época do ano); $d_{r}$ é o quadrado da razão entre a distância média Terra-Sol e a distância Terra-Sol em dado dia do ano.

Segundo Tasumi (2003), o parâmetro $d_{r}$ é determinado pela equação 3:

$$
d_{\mathrm{r}}=1+0,033 \cos \left(\mathrm{DJ} \frac{2 \pi}{365}\right)
$$

Em que: DJé o Dia Juliano do ano das imagens de satélite, em que os valores são correspondentes ao dia da geração das imagens, bem como o $d r$ e o $\cos \mathrm{Z}$.

\section{Albedo planetário:}

Segundo Silva et al (2005), o albedo planetário, o qual não é ajustado à transmisividade atmosférica, pode ser obtido através da combinação linear das reflectâncias monocromáticas com os canais reflectivos, sendo determinado pela equação 4 :

$$
\alpha_{\text {tor }}=0,293 \rho_{1}+0,274 \rho_{2}+0,233 \rho_{3}+0,157 \rho_{4}+0,033 \rho_{5}+0,011 \rho_{7}
$$

Em que: $\rho_{1} ; \rho_{2} ; \rho_{3} ; \rho_{4} ; \rho_{5}$ e $\rho_{7}$ são as reflectâncias monocromáticas das bandas $1 ; 2 ; 3 ; 4 ; 5$ e 7 , respectivamente.

\section{Albedo da superfície:}

O albedo de superfície tem ampla importância na determinação do balanço de radiação e requer correções. Para o cálculo do albedo de superfície, ou albedo corrigido, para os efeitos atmosféricos $(\alpha)$, tem-se a equação 5 (SILVA et al., 2005):

$$
\alpha=\frac{\alpha_{\mathrm{tod}}-\alpha_{\mathrm{p}}}{\tau_{\mathrm{sw}^{2}}}
$$


Em que: $\alpha_{\text {toa }}$ é o albedo no topo da atmosfera, $\alpha_{\mathrm{p}}$ é a radiação solar refletida pela atmosfera que varia de 0,025 a 0,04 , e $\tau_{\mathrm{sw}}$ é a transmissividade atmosférica.

A transmissividade atmosférica é a fração da radiação solar incidente que é transmitida pela atmosfera. Segundo Nicácio (2008), pode ser obtida através da seguinte equação 6:

$$
\tau_{\text {sw }}=0,75+2 \times 10^{-5} Z
$$

Em que: $z$ é a altitude de cada pixel (m).

Índice de vegetação ajustada ao solo (SAVI):

É um índice de vegetação que objetiva amenizar os efeitos do solo no NDVI, obtido através da seguinte equação 7 , para as imagens do Landsat 5:

$$
\operatorname{SAVI}=\frac{(1+\mathrm{L}) \times\left(\rho_{4}-\rho_{3}\right)}{\left(\mathrm{L}+\rho_{4}+\rho_{3}\right)}
$$

Em que: L um fator de ajuste ao solo, sendo uma constante que, de acordo com Allen et al. (2002), é de 0,5. Para as imagens do Landsat 8, o SAVI foi calculado pela seguinte equação 8 (HUETE, 1988):

$$
\mathrm{SAVI}=\frac{(N I R-R)}{(N I R+R+I)},(1+L)
$$

Em que: NIR é a banda do infravermelho próximo, RED é a banda do vermelho e "L" é a constante que minimiza o efeito do solo, sendo 0,5 .

\section{Índice de vegetação por diferença normalizada (NDVI):}

O NDVI é um indicador sensível da quantidade e condição da vegetação verde, podendo variar de -1 até +1 . Seu valor será obtido por meio da razão entre a diferença da reflectância do infravermelho próximo ( $\rho 4)$ e a do vermelho $(\rho 3)$, dividida pela soma de ambas (ALLEN et al., 2002), ou seja:

$$
\text { NDVI }=\frac{\rho_{4}-\rho_{3}}{\rho_{4}+\rho_{3}}
$$

Em que: $\rho 4, \rho 3$ se referem, respectivamente, às reflectâncias das bandas 4 e 3 do sensor TM Landsat 5 . Para o sensor do Landsat 8, tem-se a equação proposta por Rouse et al (1973), em que a normalização é feita da seguinte maneira:

$$
\mathrm{NDVI}=\frac{\rho N I R-\rho R E D}{\rho N I R+\rho R E D}
$$

Em que: $\rho \rho$ NIR é a reflectância para banda do Infravermelho Próximo e $\rho$ RED é a reflectância para a banda do vermelho.

\section{Resultados e discussão}

São apresentados, a seguir, os resultados obtidos pelo processamento dos dados espectrais das imagens obtidas, que foram avaliadas através de processo de interpretação visual dos mapas gerados.

O albedo da superfície foi calculado a partir da equação 5 , sendo os valores obtidos em função do albedo planetário e da transmissividade atmosférica, os quais podem variar de acordo com as características físico-químicas das superfícies estudadas e com o ângulo zenital, assim como as atividades antrópicas existentes no local.

Analisando o mapa da figura 1, observa-se que os valores obtidos para albedo da superfície, referente ao ano de 2006, estão concentrados entre os valores de 0,11 e 0,21 , podendo indicar a presença de corpos hídricos e área úmida na região. 
Análise do albedo da superfície e de índices de vegetação por sensoriamento remoto na bacia hidrográfica do Rio Pacoti/CE

Figura 1 - Albedo da superfície na bacia hidrográfica do Rio Pacoti/CE no ano de 2006.

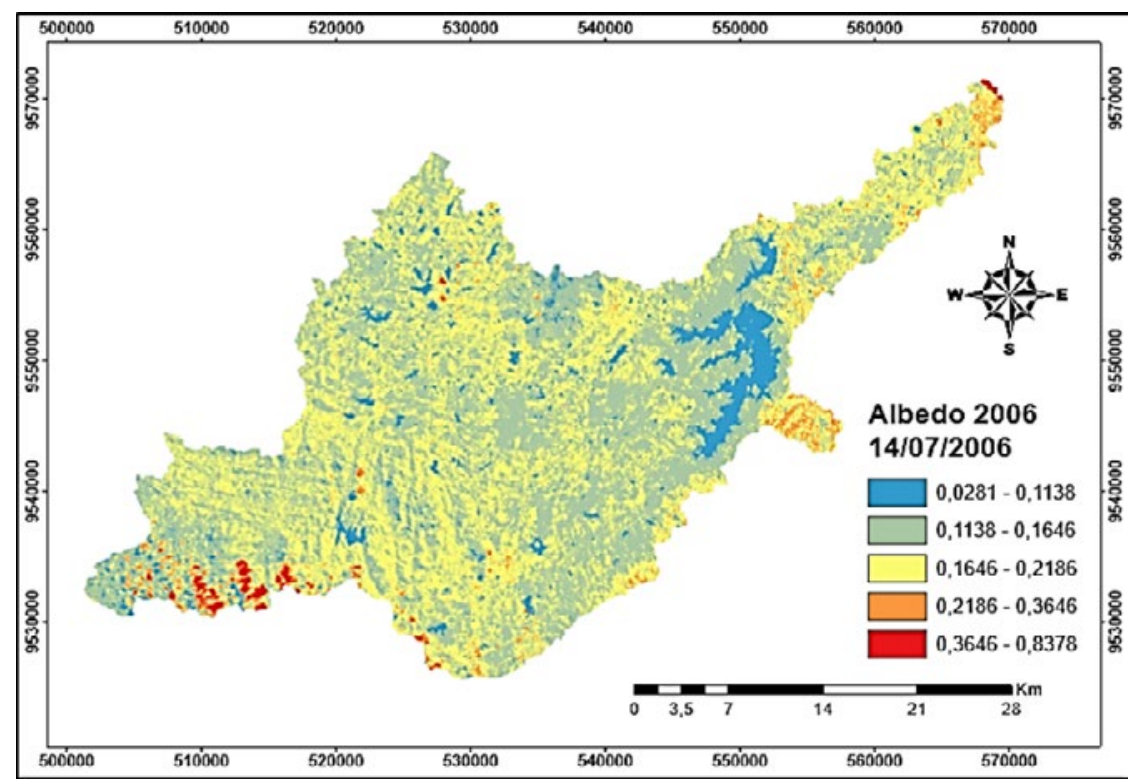

Fonte: Elaborado pelo autor.

Estudos em reservatórios e açudes, como o de Silva et al (2005), cujos valores situam-se entre 0,09 a 0,12, indicam a presença de áreas irrigadas com fruteiras (manga, banana, goiaba, uva, etc.), sendo designadas as áreas intermediárias aos reservatórios, rios e corpos hídricos como os existentes na área estudada, em que os valores encontrados no presente trabalho, de 0,11 a 0,16, indicam solos úmidos na região. Cunha et al (2012) obteve valores significativos entre 0,12 e 0,21. Esse resultado é decorrente dos meses anteriores, que tiveram quadra chuvosa relativamente alta, como consta na tabela 3.

Tabela 3 - Precipitação mensal na bacia do Rio Pacoti/CE, no ano de 2006.

\begin{tabular}{c|c|c|c|c|c|c|c}
\hline Ano de 2006 & Janeiro & Fevereiro & Março & Abril & Maio & Junho & Julho \\
\hline Chuvas (mm) & 16.0 & 105.2 & 117.1 & 109.6 & 91.1 & 22.7 & 0.0 \\
\hline
\end{tabular}

Fonte: Funceme (2018).

Verificou-se, na figura 1, os valores de albedo da superfície, no ano de 2006, de 0,21 para áreas com pouca vegetação e de 0,36 para áreas que indicam a presença de solos expostos na bacia hidrográfica do Rio Pacoti/CE, sendo semelhante ao resultado encontrado por Cunha et al (2012). O autor relatou em seu estudo, realizado na Paraíba, cuja bacia tem características similares a do presente estudo, valores próximos a 0,24 em áreas com pouca vegetação e valores altos para o albedo da superfície, em torno de 0,33 a 0,39 , na presença de solo exposto.

Além de solo exposto e áreas com pouca vegetação, os valores encontrados entre 0,21 e 0,36 podem significar áreas com resposta espectral para regiões antropizadas (comunidades rurais), pois semelhantes resultados foram por Giongo e Vettorazzi (2014), que obtiveram resultados significantes acima de 0,31 para áreas específicas, como áreas urbanizadas e áreas antropizadas.

Ao serem analisados os parâmetros obtidos da variável em estudo na figura 2, os valores das classes são próximos aos do ano anterior a 2006, como se pode ver na figura 1. Tal afirmação se deve ao fato do pequeno intervalo de tempo entre as amostras (14/07/2006 e 03/09/2007), de pouco mais de um ano. 
Figura 2 - Albedo da superfície na bacia hidrográfica do Rio Pacoti/CE no ano de 2007.

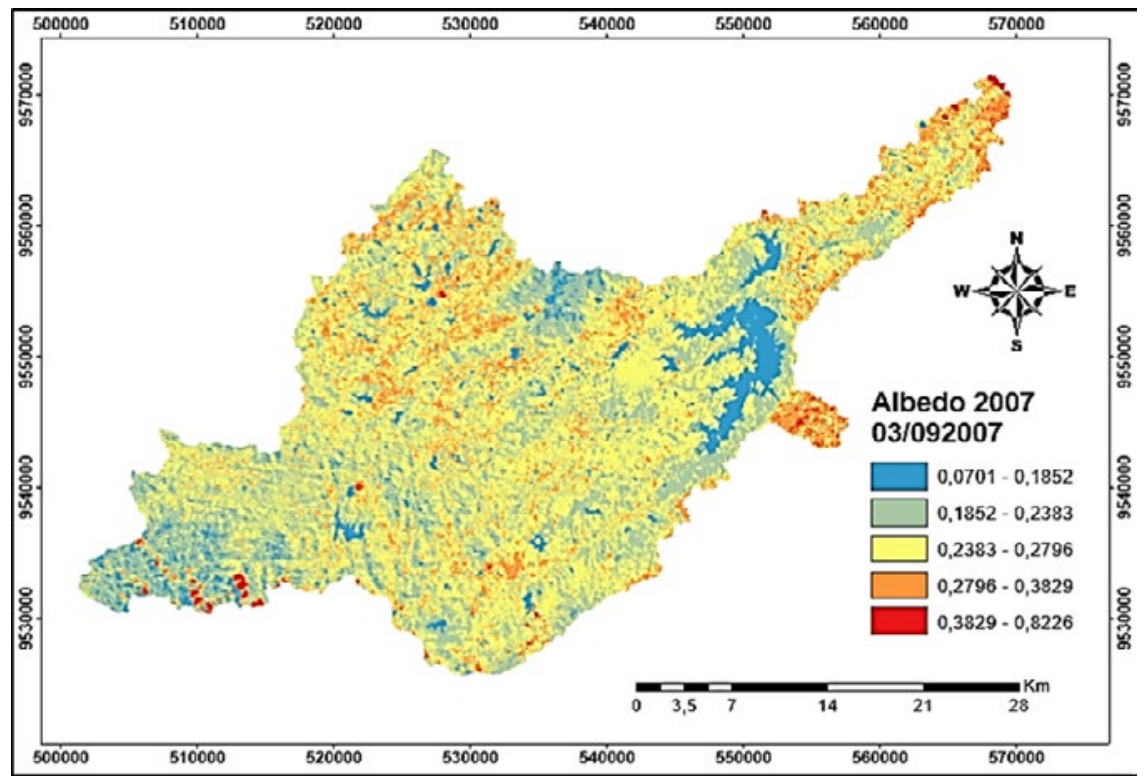

Fonte: Elaborado pelo autor.

Um fator determinante para a diferença entre os intervalos de albedo nos dois anos analisados (2006 e 2007) é a precipitação local na bacia do Rio Pacoti, demonstrada na tabela 4, em que é possível verificar a quantidade de chuvas, em $\mathrm{mm}$, ocorridas no ano de 2007.

Tabela 4 - Precipitação mensal na bacia do Rio Pacoti/CE no ano de 2007.

\begin{tabular}{l|c|c|c|c|c|c|c|c|c}
\hline Ano de 2007 & Janeiro & Fevereiro & Março & Abril & Maio & Junho & Julho & Agosto & Setembro \\
\hline Chuvas (mm) & 11.1 & 282.6 & 51.3 & 60.3 & 17.3 & 1.6 & 0.0 & 0.0 & 0.0 \\
\hline
\end{tabular}

Fonte: Funceme (2018).

Como pode ser analisado, existe uma diminuição no volume de precipitação na bacia hidrográfica estudada ao longo dos meses, tendo o mês de fevereiro como pico e estando acima da média da quadra chuvosa, no ano de 2007, em que o esperado seria chover $90.1 \mathrm{~mm}$ (Funceme, 2018). Assim, o pico das chuvas, no ano de 2007, situa-se sete meses antes da passagem do satélite Landsat 5 pela região estudada.

As chuvas não se mantiveram acima da média nos meses seguintes, causando um período de seca antes da amostragem da Figura 2. A diminuição da precipitação pode explicar o aumento de algumas classes do albedo da superfície no mapa. Por exemplo, os valores de solo exposto, nos intervalos entre 0,27 a 0,38 , que corroboram com os valores encontrados por Gomes (2009), que encontrou os valores de albedo na faixa de 0,24 a 0,27 . Nessa pesquisa, de 0,07 a 0,18 , indicam a presença de corpos hídricos, rios e riachos existentes na região, como o próprio Rio Pacoti e o açude Gavião, que se destacam nos mapas elaborados (Giongo e Vettorazzi, 2014; Dantas, 2013; Gomes, 2009; Silva et al. 2005).

A classe de intervalos entre 0,23 a e 0,27 representam áreas com pouca vegetação e áreas antropizadas, representando cidades (Pacajus, Aquiraz, Horizonte, Pacoti, Guaiúba, Itaitinga) e áreas urbanizadas, aproximando-se dos valores obtidos por Dantas (2013). Na , é possível analisar o albedo da superfície da área estudada para o ano de 2015. As alterações em algumas classes de intervalos no mapa estão relacionadas com a diferença de tempo entre as amostras (oito anos) e com o fator da precipitação, pois os anos anteriores foram de seca, ou seja, a precipitação anual foi abaixo da média, como pode ser observado na tabela 5 . 
Tabela 5 - Precipitação anual na bacia hidrográfica do Rio Pacoti/CE.

\begin{tabular}{c|c|c|c|c|c|c|c}
\hline Anos & 2008 & 2009 & 2010 & 2011 & 2012 & 2013 & 2014 \\
\hline Chuva (mm) & 748.9 & 691.3 & 474.7 & 694.1 & 251.3 & 307.6 & 367.8 \\
\hline
\end{tabular}

Fonte: Funceme (2018)

Era esperada uma precipitação anual de $505.1 \mathrm{~mm}$ nos anos de 2012, 2013 e 2014 (Funceme, 2018), mas, analisando a tabela 5, é possível identificar que o volume de precipitação relacionado a cada esses ano foi muito abaixo do esperado, causando um período de estiagem na região, que se refletiu nas classes de albedo da superfície, como pode se verificar na figura 3.

Figura 3 - Albedo da superfície na bacia hidrográfica do Rio Pacoti/CE no ano de 2015.

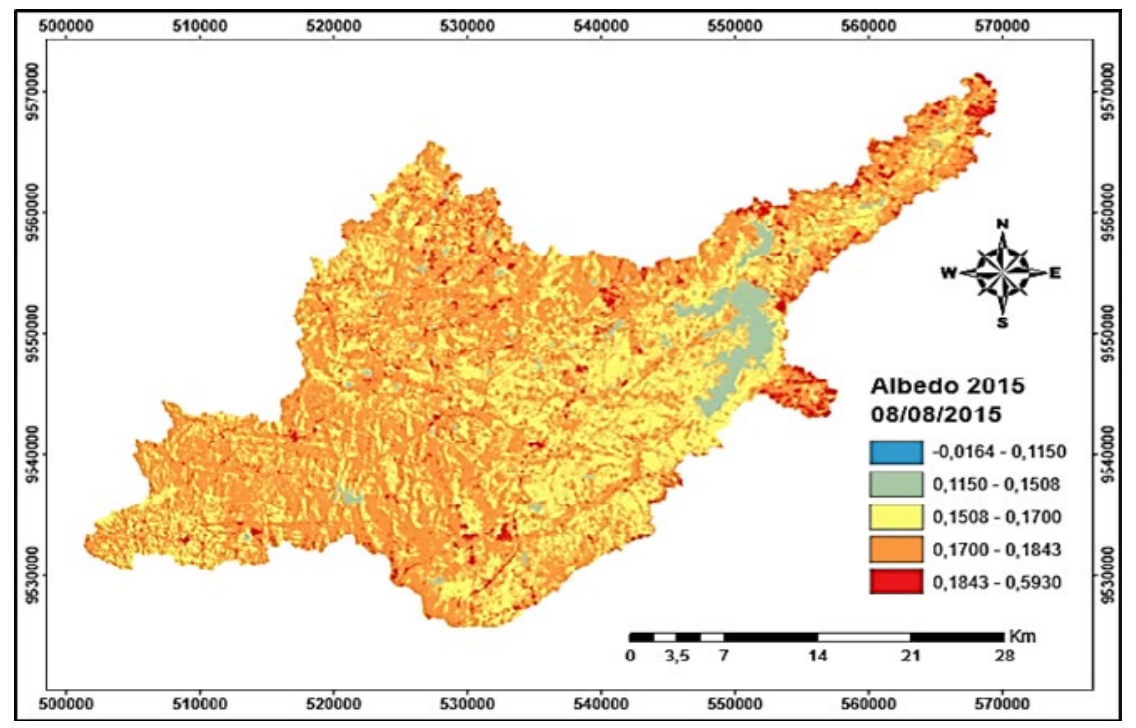

Fonte: Elaborado pelo autor.

Segundo Ideão (2009), a redução da cobertura vegetal também aumenta o valor do albedo sobre circunstâncias específicas. Deste modo, o aumento do albedo reduz a precipitação local, intensificando os processos de degradação ambiental, além o aumento do uso e ocupação do solo na região.

Como denotado na figura 3, os albedos da superfície de valores altos ganharam proporção na imagem da bacia hidrográfica do Rio Pacoti e podem estar diretamente ligados à diminuição das chuvas nos anos anteriores. Com a passagem dos anos entre as imagens analisadas, outra vertente que se destaca é o crescimento da agricultura local.

No mapa figura 3, os valores obtidos de albedo da superfície, que estão situados entre 0,17 e 0,18 , podem representar o aumento da agricultura local na região (banana, feijão, milho, cana-de-açúcar). Há relatos de que áreas com cana-deaçúcar apresentam albedo na faixa de 0,16 a 0,20 (Gomes, 2009). No entanto, também podem ser observados valores entre 0,18 a 0,22 , os quais podem representar pastagens, áreas com grande densidade de plantio e agricultura (SILVA et al., 2005; CARAM, 2010).

Os valores de albedo da superfície que melhor representa a caatinga estão situados na faixa em torno de 0,20 a 0,30 , em que os solos são mais descobertos. O presente estudo relatou que áreas que representam a caatinga estão localizadas na classe de intervalo com valores que variam entre 0,18 a 0,59. Para confirmação dessa afirmação, seria necessário realizar uma classificação supervisionada da bacia estudada, uma classificação em que é necessária uma visitação ao local com conhecimento prévio da região e o auxílio de GPS para aquisição das coordenadas. Os valores entre 0,18 a 0,59 , que estão compreendidos nesse intervalo de albedo da superfície, estão situados em um intervalo bem abrangente, podendo existir vários tipos de culturas e significados para eles.

O NDVI foi calculado através das equações 9 e 10 em função das reflectâncias das bandas 4 e 3 para as imagens obtidas pelo Landsat 5, e as bandas 4 e 5 para aquelas obtidas pelo Landsat 8 . Tal cálculo é um importante indicador de 
desertificação e redução de biomassa, com valores alterando entre -1 (para regiões que representam áreas com pouca vegetação) a 1 (para as regiões que representam áreas com maiores quantidades de vegetação).

Como o NDVI é um índice de vegetação, torna-se importante o conhecimento dos tipos de vegetação que ocorrem na área do referente estudo. Logo, segundo Crispim (2011), as principais unidades fitoecológicas, identificadas na área da bacia hidrográfica do Pacoti, são: complexo vegetal litorâneo, mata ciliar e lacustre, floresta tropical subcaducifólica (mata seca), floresta subperenifólia (mata úmida) e a caatinga.

Analisando os mapas das fig. 4 e 5, o NDVI tem predominância nas classes de 0,47 a 0,65 e de 0,65 a 0,96, significando vegetação esparsa e vegetação nativa densa (Meirelles, 2007; Bezerra, 2006; Braz, Águas e Garcia, 2015; Lima et al., 2017). Mas, por ser um intervalo bem amplo, alguns valores para culturas e áreas irrigadas, entre outros parâmetros, podem estar relacionados com esses intervalos, conforme pode ser visualizado nas figura 4 e 5 .

Figura 4 - NDVI da bacia hidrográfica do Rio Pacoti/CE no ano de 2006.

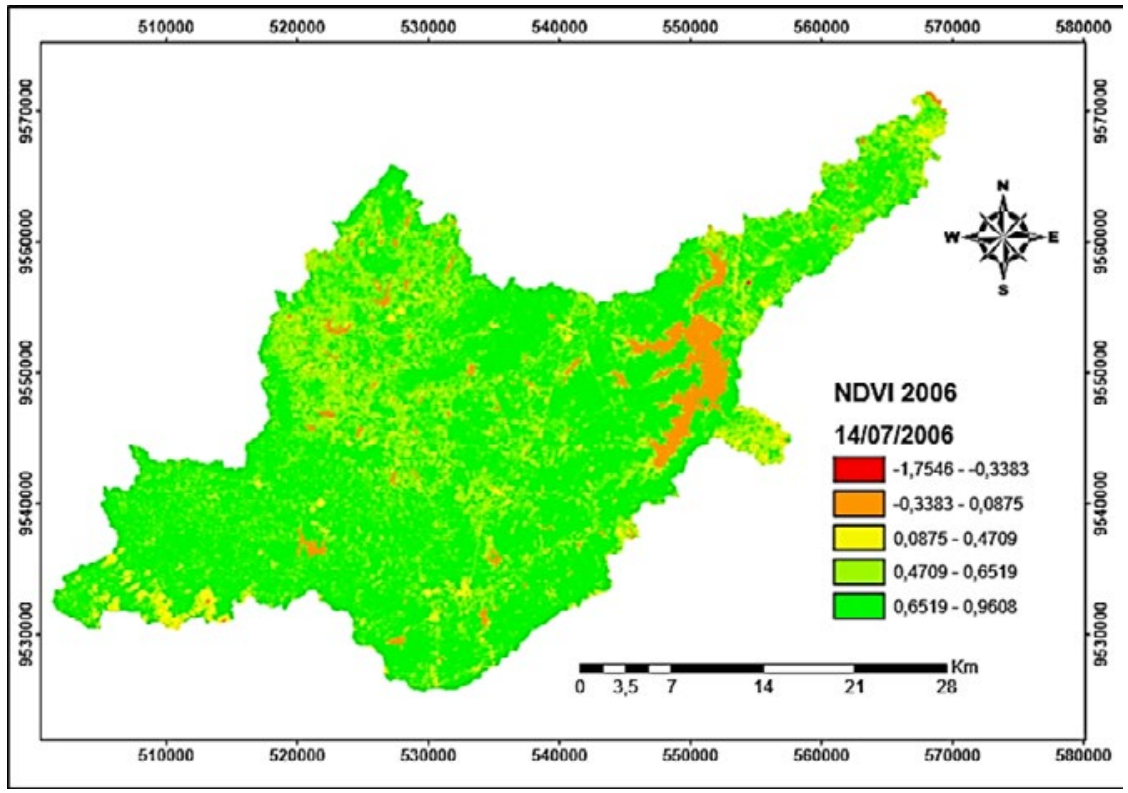

Fonte: Elaborado pelo Autor.

Figura 5 - NDVI da bacia hidrográfica do Rio Pacoti/CE no ano de 2007.

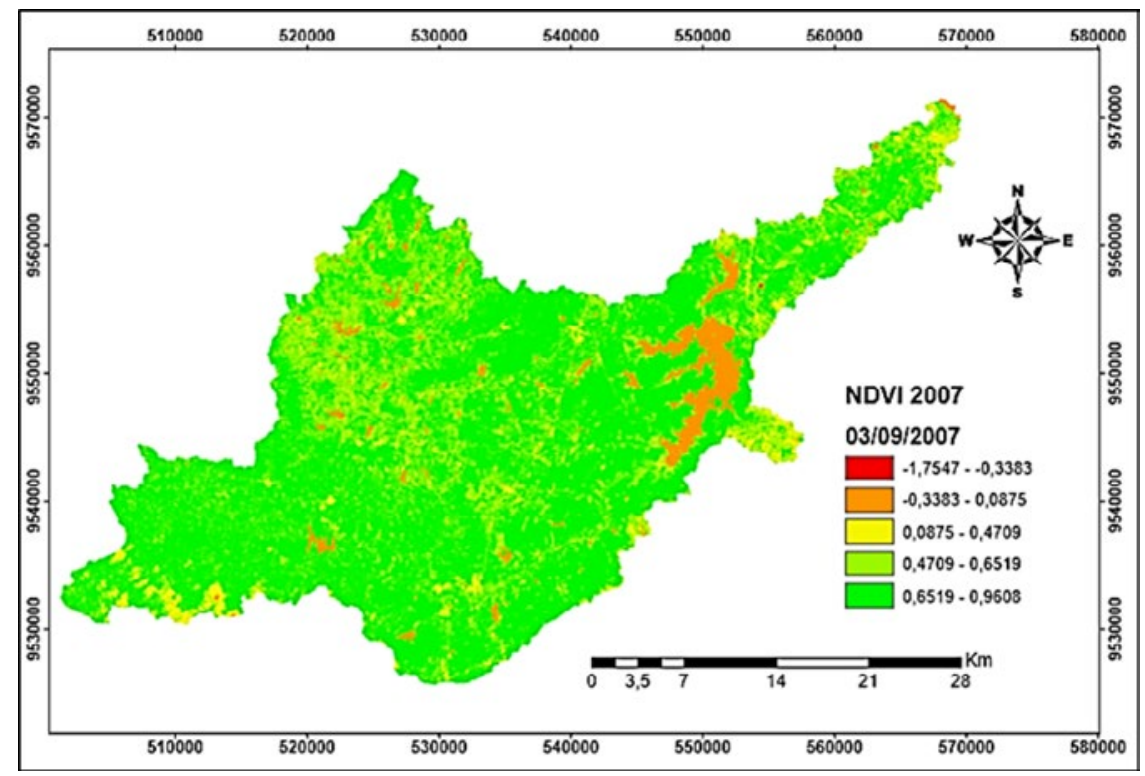

Fonte: Elaborado pelo autor. 
Os resultados obtidos em áreas com vegetação nativa densa são superiores (próximos a 1) em comparação aos de áreas antrópicas (próximos a 0). Esse comportamento é válido, uma vez que o índice de vegetação por diferença normalizada apresenta maiores valores. Os anos de 2006 e 2007, conforme figuras 4 e 5, apresentam pouca diferenciação entre classes. Deste modo possuem o intervalo de valores entre 0,08 a 0,47 . Por serem bastante abrangentes, podem apresentar algumas culturas e vegetação rala. Assim, de acordo com Zanzarini et al (2013), valores entre 0,21 a 0,49 podem ser considerados para algumas culturas, como a cana-de-açúcar.

Segundo Dantas (2013), os valores negativos de NDVI estão associados a nuvens, água ou neve, pois esses alvos refletem mais intensamente o canal vermelho, evidenciados na figura 8 , em que os valores negativos, ou próximos de 0 , indicam a presença de corpos hídricos, como rios, riachos e o açude Gavião. $\mathrm{O}$ intervalo de 0,08 a 0,47 também pode estar relacionado à vegetação tipo caatinga, corroborando com Nascimento e Araújo (2014), que realizaram um estudo na região Oeste Potiguar e encontraram valores entre 0,20 e 0,35 , correspondentes à vegetação do tipo caatinga, e valores entre 0,30 a 0,50 , que são observados para a vegetação nativa.

Já para os anos de 2015, 2016 e 2017, conforme figuras 6,7 e 8 o NDVI teve algumas diferenças em suas classes, o que pode ser causado pela degradação ocorrida durante o espaço temporal das amostras, avanço de culturas, pela precipitação abaixo da média nos anos anteriores e pelo aumento do uso e ocupação da região. Segundo Crispim (2011), a degradação ambiental na bacia hidrográfica do Rio Pacoti é nítida, sendo intensificada pelas atividades socioeconômicas, de maneira que é necessário avaliar essas atividades a fim de dar suporte aos sistemas ambientais vulneráveis.

Figura 6 - NDVI da bacia hidrográfica do Rio Pacoti/CE no ano de 2015.

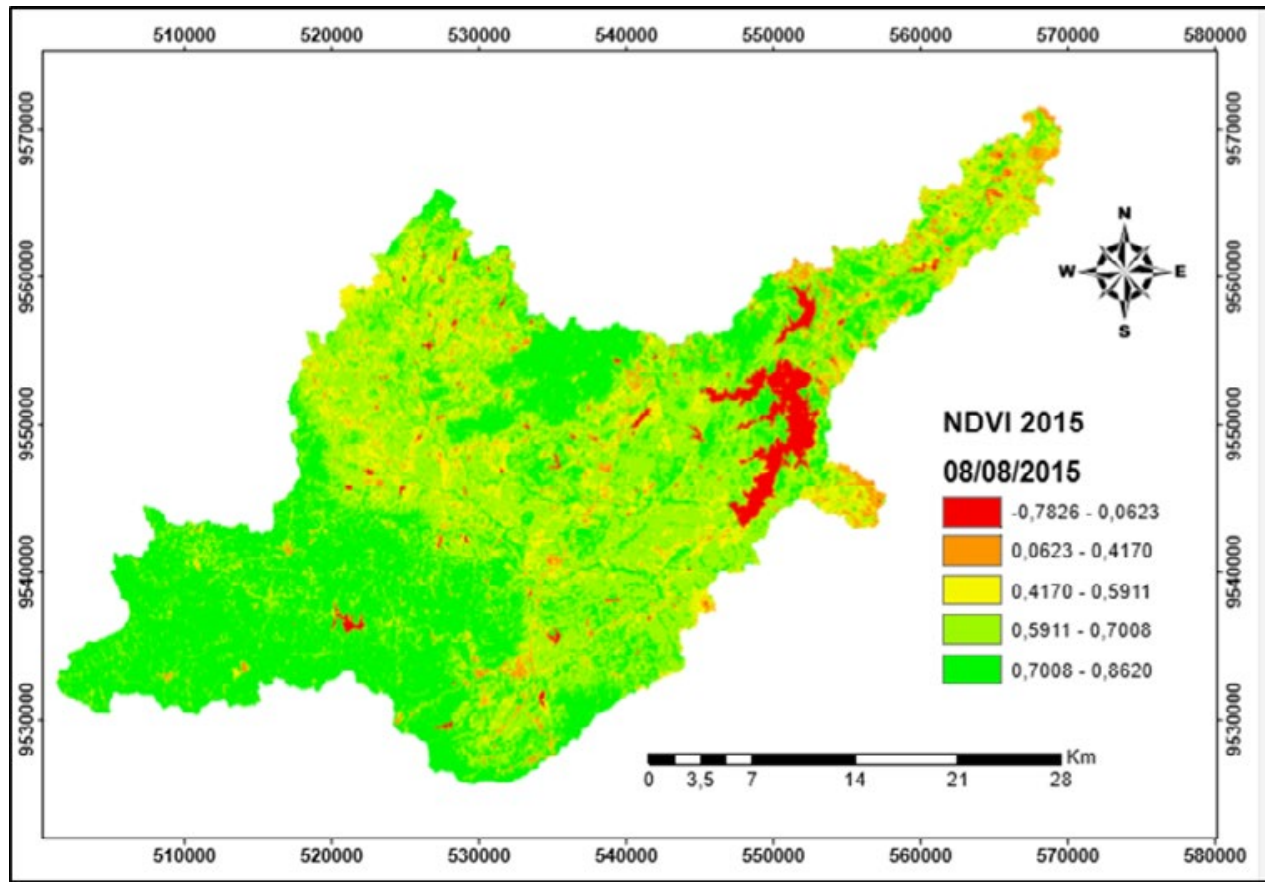

Fonte: Elaborado pelo autor 
Figura 7 - NDVI da bacia hidrográfica do Rio Pacoti/CE no ano de 2016.

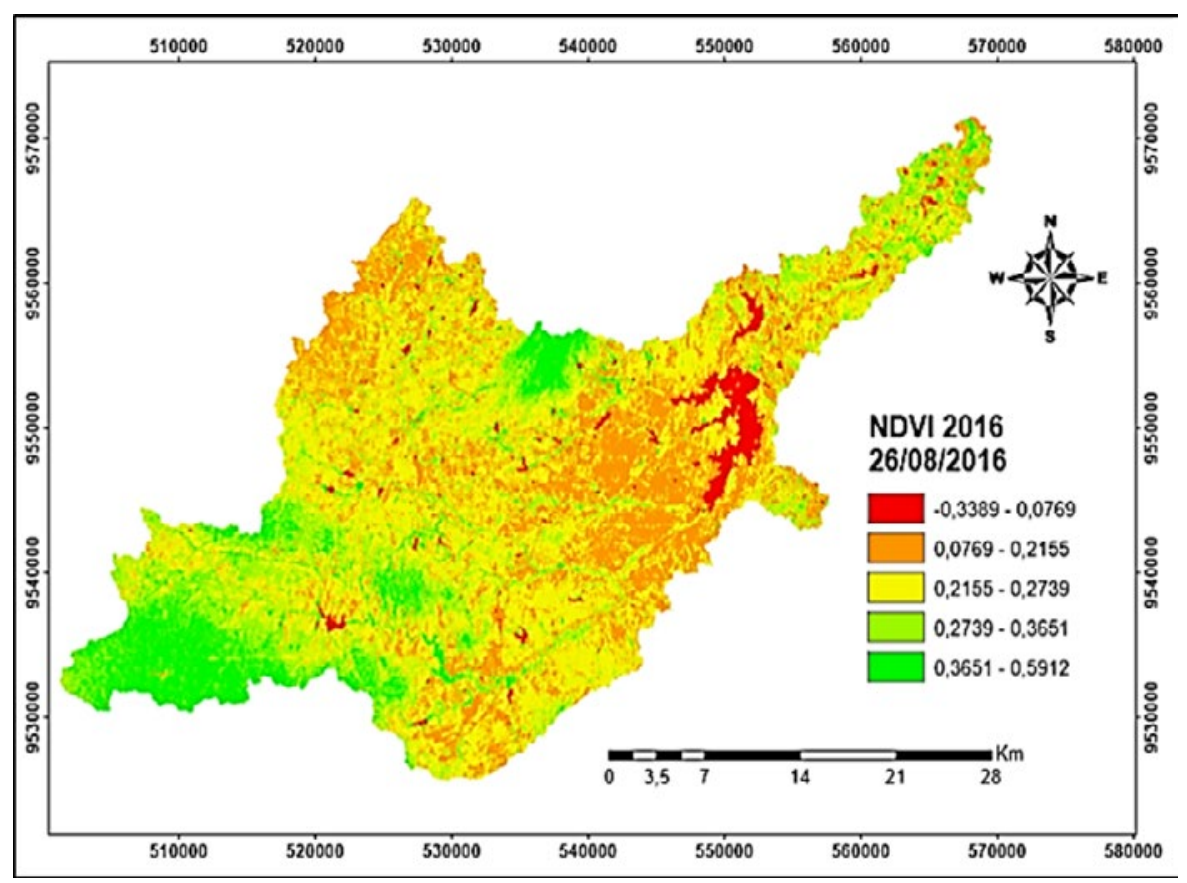

Fonte: Elaborado pelo autor

Figura 8 - NDVI da bacia hidrográfica do Rio Pacoti/CE no ano de 2017.

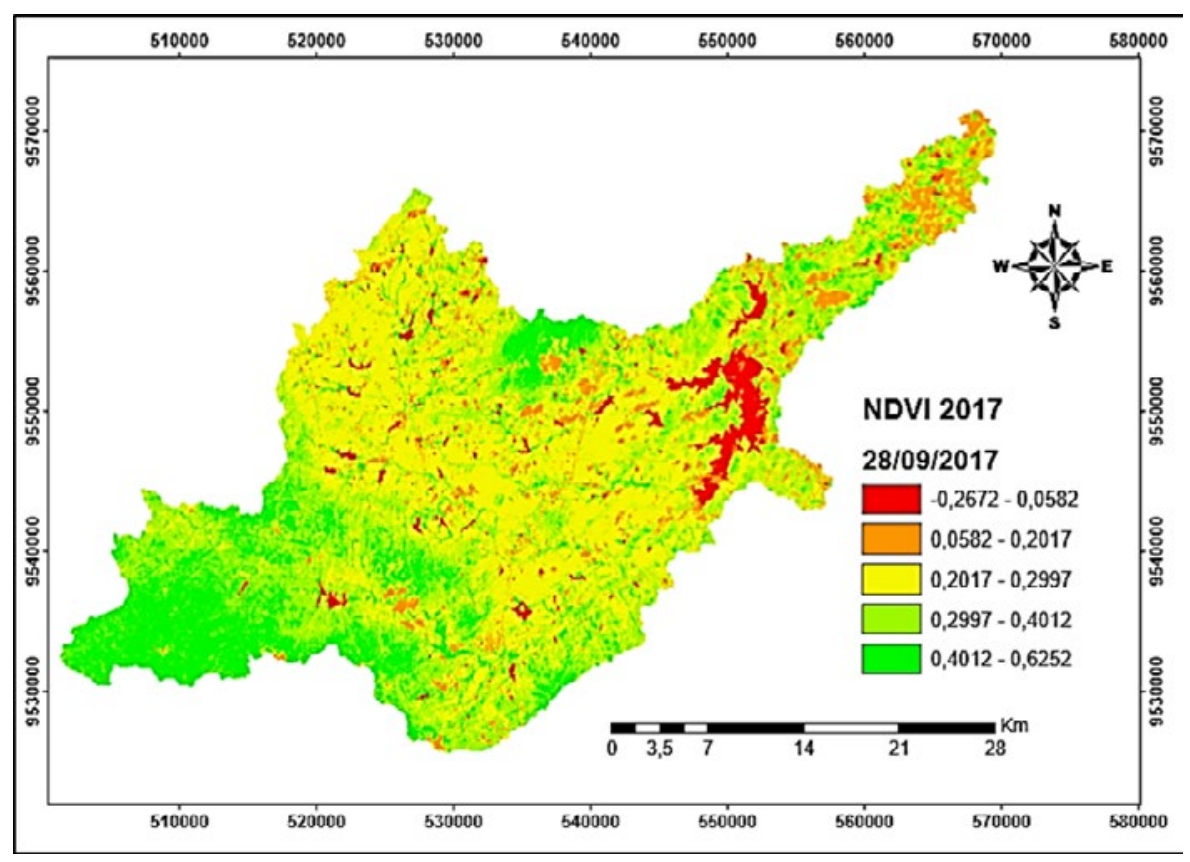

Fonte: Elaborado pelo autor

Analisando os mapas das figura 6,7 e 8, é evidente o aumento nas proporções do intervalo de valores entre $0,06 \mathrm{e}$ 0,41 para o ano de 2015, evidenciando o aumento de solo exposto e vegetação rala na região do estudo, relacionando-se com o estudo de Braz, Águas e Garcia (2015), que encontrou valores similares para pastagens.

Confirma-se, nos anos seguintes, o aumento desses campos abertos, assim como o aumento de solo exposto na região da bacia hidrográfica Rio Pacoti para os anos de 2016 e 2017, conforme figuras 7 e 8, com predominância nos valores de 
classes entre 0,21 e 0,29. Logo, evidenciado tal aumento, pode-se realizar uma comparação com o estudo de Nicácio (2008), que encontrou resultados com valores próximos a 0,15 para representar solo nu (exposto). Outra pesquisa, análoga a esta é a de Dantas (2013), que encontrou valores de NDVI para vegetação rala entre 0,27 e 0,47 em áreas consideradas como de caatinga densa, característica em regiões semiáridas, podendo ser comparado com as grandes áreas, em que esse valor é representado na Fig. 9, fixando-se nos intervalos entre 0,06 e 0,41 para o ano de 2015; 0,21 e 0,36 para o ano de 2016, e entre 0,20 e 0,40 para o ano de 2017. É compreensível que tais valores estejam relacionados ao aumento de culturas, aos anos anteriores de estiagem e à degradação ocorrida.

O SAVI foi calculado de acordo com as equações 7 e 8 , em função das reflectâncias das bandas 3 e 4 para as imagens obtidas do satélite Landsat 5 e das bandas 4 (RED) e 5 (NIR) do Landsat 8, além do fator de ajuste do solo, o qual, neste estudo, foi considerado como sendo 0,1 , sendo apresentado como crítico na minimização dos efeitos das propriedades ópticas do solo, na refletância da vegetação.

Analisando os mapas das figuras 9 e 10, observa-se um domínio de classe no intervalo entre 0,52 e 0,83 , demonstrando uma grande área vegetada para esses anos (2006 e 2007), corroborando com Braz, Águas e Garcia (2015), que obtiveram resultados entre 0,55 e 1,49, apresentando valores altos, portanto, em virtude do índice de vegetação SAVI ser em função da constante "L", a qual diminuiu a influência da resposta espectral do solo. Ideão (2009) afirma que o SAVI é utilizado para fazer o ajuste do solo, já que as suas características têm considerável influência no espectro de radiação, proveniente de dosséis vegetais esparsos.

Figura 9 - SAVI da bacia hidrográfica do Rio Pacoti no ano de 2006.

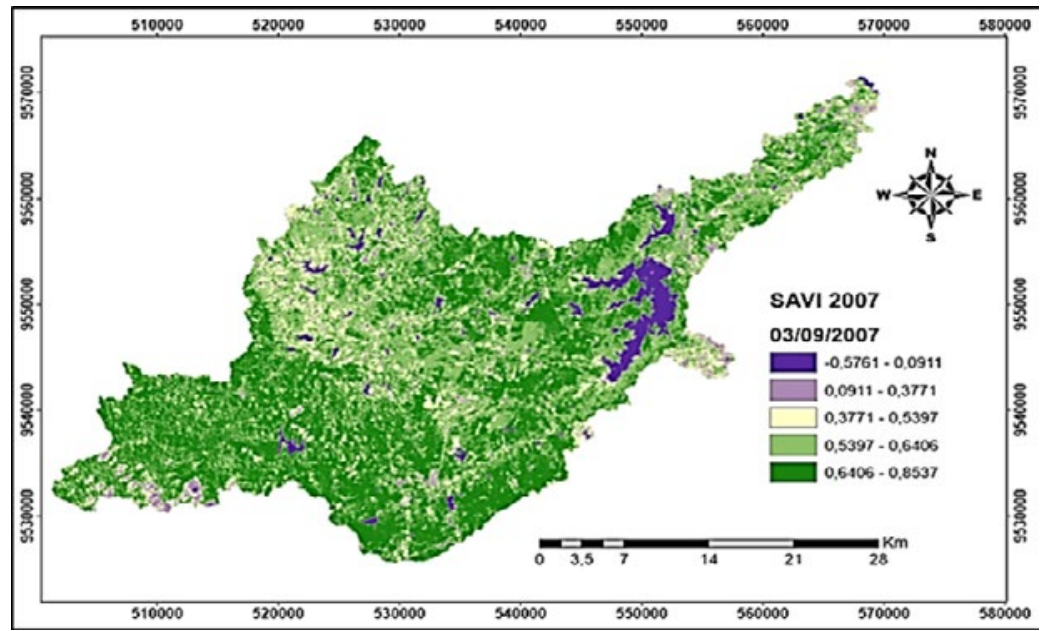

Fonte: Elaborado pelo autor.

Figura 10: SAVI da bacia hidrográfica do Rio Pacoti no ano de 2007.

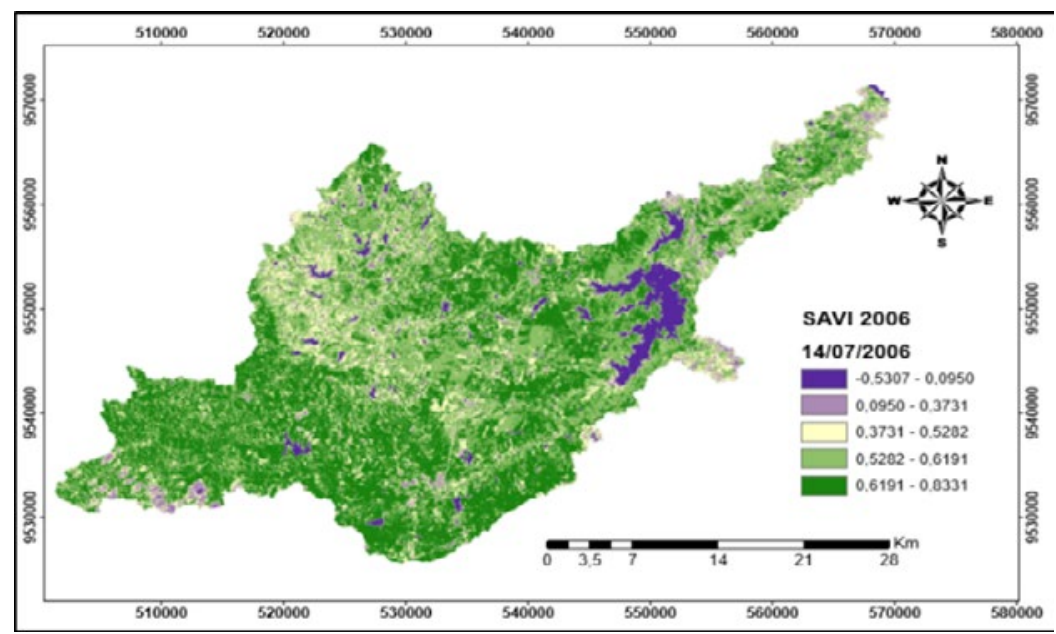

Fonte: Elaborado pelo autor. 
Os valores inferiores a 0 indicam presença de corpos hídricos ou nuvens, que podem ser encontrados no açude Gavião e em áreas com presença de rios. Valores baixos, como de 0,09 a 0,37, conforme figuras 9 e 10, indicam solos expostos, e acima de 0,5 para áreas vegetadas, sendo relacionados com o trabalho de Pavão et al (2016) e de Ideão (2009). Já para campos e cidades, os valores ocorreram entre 0,3 e 0,45 .

De acordo com a análise do mapas das figuras 11, 12 e 13 para os anos de 2015, 2016 e 2017, percebe-se uma diminuição na área vegetada significativa da região da bacia hidrográfica do Rio Pacoti. A classe no intervalo de $0,52 \mathrm{e}$ 0,83 , que na figura 10 (anos de 2006 e 2007) teve maior dominância, por sua vez, nos mapas mais atuais, recebe pouca porcentagem nas amostras, significando uma degradação da área vegetada em circunstância da passagem dos anos, do aumento de culturas e da precipitação abaixo da média, como é possível visualizar na tabela 6 .

Tabela 6 - Precipitação mensal na bacia do Rio Pacoti/CE nos anos de 2015, 2016 e 2017.

\begin{tabular}{cccccccccc}
\hline Chuvas $(\mathrm{mm})$ & Janeiro & Fevereiro & Março & Abril & Maio & Junho & Julho & Agosto & Setembro \\
\hline 2015 & 35.6 & 83.3 & 135.9 & 38.2 & 36.5 & 33.5 & 2.2 & 0.0 & 0.0 \\
\hline 2016 & 265.4 & 13.7 & 91.2 & 24.8 & 57.1 & 1.4 & 0.0 & 0.0 & 0.0 \\
\hline 2017 & 46.5 & 102.6 & 124.5 & 54.8 & 12.3 & 6.4 & 1.0 & 0.0 & 0.0 \\
\hline
\end{tabular}

Fonte: Funceme (2018).

Para esses anos, era esperada uma maior precipitação para os meses antes da passagem do satélite, assim continuando o período de estiagem na região. Logo, analisaram-se os valores do índice de vegetação SAVI, variando de - 0,5 a 0,13, no qual representam áreas não vegetadas, seguido pelo intervalo entre 0,13 e 0,30 para áreas de pastagem e antropizadas, estando de acordo com os resultados obtidos por Magalhães, Carvalho Júnior e Santos (2017).

Figura 11 - SAVI da bacia hidrográfica do Rio Pacoti/CE no ano de 2015.

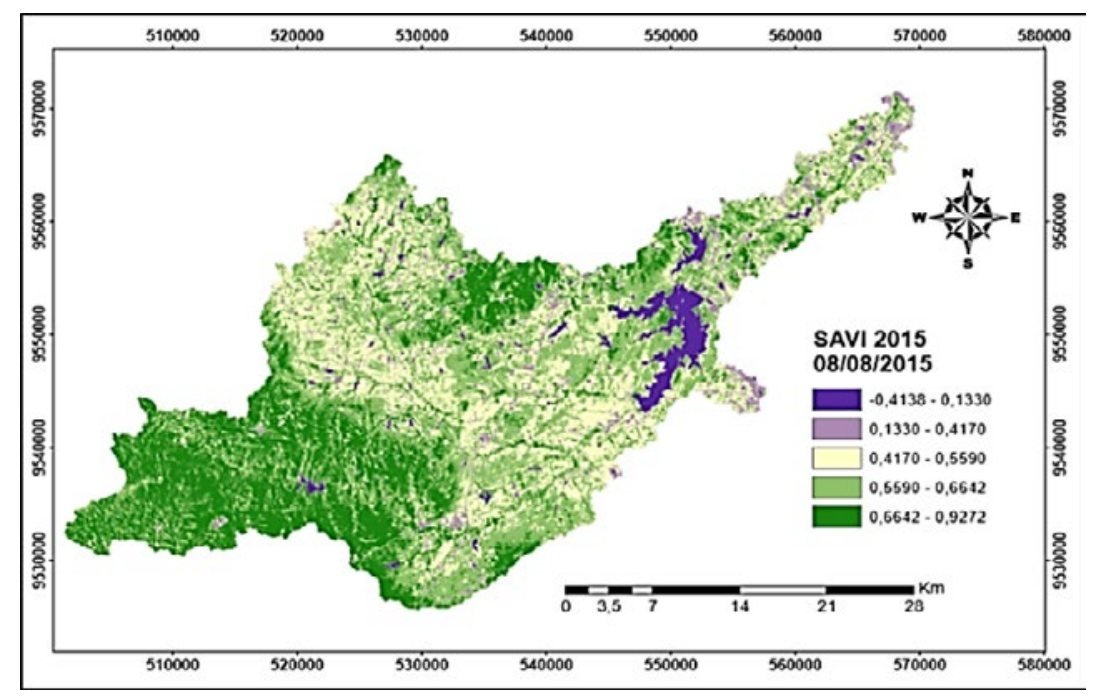

Fonte: Elaborado pelo autor. 
Análise do albedo da superfície e de índices de vegetação por sensoriamento remoto na bacia hidrográfica do Rio Pacoti/CE

Figura 12 - SAVI da bacia hidrográfica do Rio Pacoti/CE no ano de 2016.

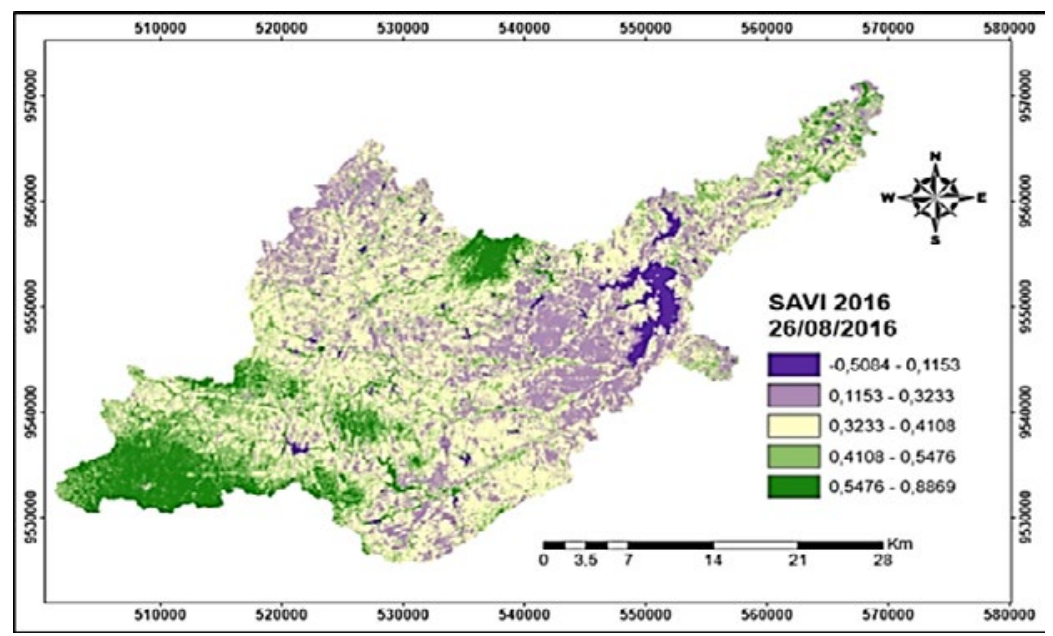

Fonte: Elaborado pelo autor.

Figura 13 - SAVI da bacia hidrográfica do Rio Pacoti/CE no ano de 2017.

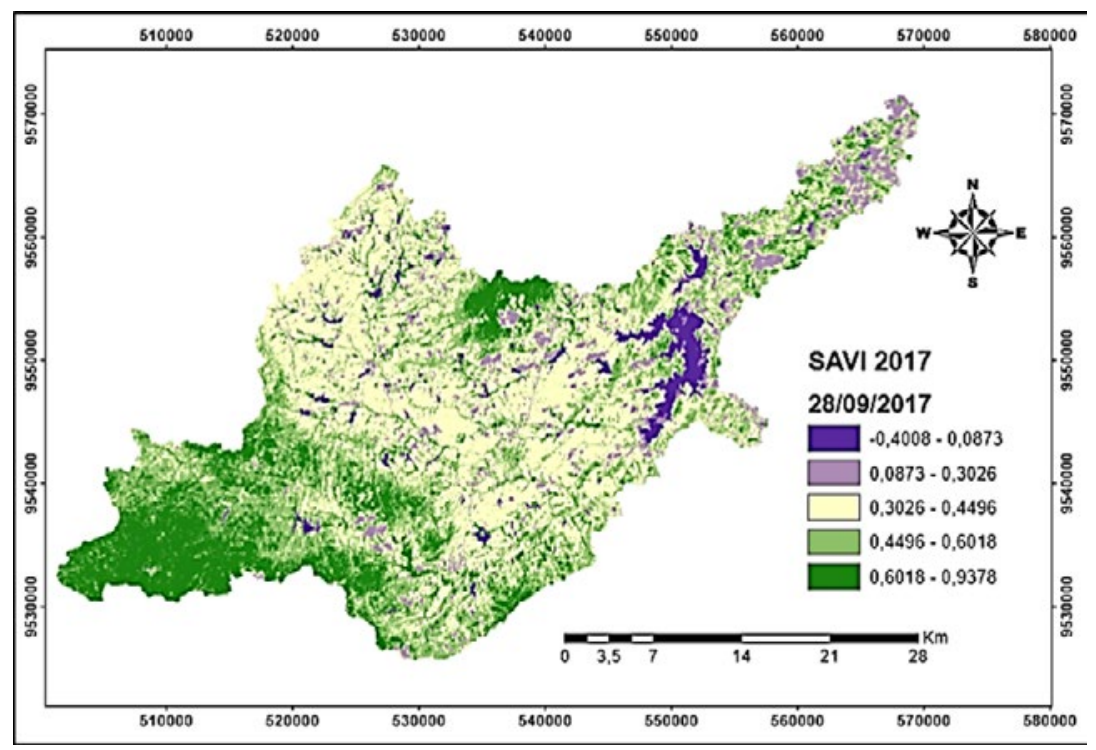

Fonte: Elaborado pelo autor.

Áreas com valores de intervalo de 0,60 a 0,93 podem indicar a presença de vegetação com um porte maior, e intervalos situados de 0,15 a 0,20 podem indicar áreas degradadas ou em processo de degradação, assemelhando-se ao estudo elaborado por Francisco et al (2015), que encontrou valores entre 0,80 e 0,85 . Os intervalos de 0,20 a 0,40 podem representar regiões com vegetações abertas, áreas degradadas ou caatinga, assemelhando-se ao estudo realizado por Dantas, Nascimento e Braga (2012), em que a maioria dos valores ficou nas casas entre 0,15 e 0,35 , representando a caatinga e demonstrando a grande amplitude a que esse tipo de vegetação pode chegar nesse índice. Algumas atividades agrícolas também podem ser representadas pelo intervalo de classes entre 0,2 e 0,4, de acordo com Demarchi, Piroli e Zimback (2011). Os valores situados entre 0,2 e 0,3 representam áreas com cobertura vegetal escassa, cultivo de laranja, cana-de-açúcar e diversas outras culturas anuais. Já áreas com vegetação arbórea e culturas agrícolas de cobertura vegetal densa ficam restritas ao intervalo de 0,2 a 0,6, valores que têm maior proporção no mapa analisado na figura 7 (anos de 2015, 2016 e 2017). 


\section{Conclusão}

Ocorreram diferenças significativas entre as classes de valores para as variáveis em análise, decorrente da oscilação anual entre as amostras, oscilação nas quadras chuvosas e da degradação sofrida na região. Para a variável albedo da superfície, houve pouca diferença nas classes entre os anos de 2006 e 2007, e uma variação maior para o ano de 2015, principalmente para os intervalos que representam as culturas cultivadas na região.

O NDVI e SAVI variaram bastante nos anos analisados, tendo uma diminuição da área vegetada significativa e um acréscimo da porção, que representa solo exposto, evidenciando a degradação sofrida na região.

Assim, vale salientar que o uso das técnicas de sensoriamento remoto, sistema de informação geográfica - SIG e geoprocessamento possibilitam a obtenção e a espacialização do albedo da superfície e índices de vegetação, sendo ferramentas que podem ser usadas no planejamento e na gestão do uso do solo e dos recursos hídricos, gerando um manejo ambiental adequado em uma bacia hidrográfica.

Recomenda-se medidas de manejo adequadas e ações mitigadoras para recuperação das áreas impactadas. A adoção de práticas regulatórias, medidas de controle e recuperação ambiental tornam-se necessárias na busca de melhor qualidade de vida da população e da utilização dos recursos de forma sustentável.

\section{Referências}

ALLEN, R. G. et al. Surface energy balance algorithms for land - Advanced training and user's manual. Idaho: NASA EOSDIS. Versão 1.0, p. 98, 2002.Disponível em: https://www.researchgate.net/file.PostFileLoader.html?id=563 5f25060614b180d8b4567\&assetKey=AS\%3A290936253894656\%401446376016229. Acesso em: 12 abr. 2018.

BANDEIRA, T. V. et al. O geoprocessamento na delimitação da Sub-Bacia Hidrográfica do Rio Júa, CaucaiaCeará. 2017. Disponível em: <https://drive. google.com/file/d/0B9cQbhL617PHWjBlWVoxcWVSY0k/view>. Acesso em: 14 out. 2017.

BEZERRA, B. Guedes. Balanço de energia e evapotranspiração em áreas com diferentes tipos de cobertura de solo no Cariri cearense através do algoritmo Ssebal. 2006. Dissertação (Mestrado em Metereologia) - Universidade Federal de Campina Grande, Campina Grande, 2006. Disponível em: <http://www.dca.ufcg.edu.br/posgrad_met/ dissertacoes/BergsonGBezerra_2006.pdf>. Acesso em: 12 abr. 2018.

BRAZ, Adalto M.; ÁGUAS, Thiago de A.; GARCIA, Patricia H. Mirandola. Análise de índices de vegetação NDVI e SAVI e índice de área folear (IAF) para a comparação da cobertura vegetal na Bacia Hidrográfica do Córrego Ribeirãozinho, Município de Sselvíria - MS. 2015. Disponível em: <http://periodicos.uem.br/ojs/index.php/Percurso/ article/view/28758>. Acesso em: 12 abr. 2018.

CARAM, Rochene de O. Mudanças no uso e cobertura do solo e resposta hidrológica da Bacia do Rio Piracicaba. 2010. 140 f. Tese (Doutorado em Agricultura) - Curso de Agricultura, Universidade de São Paulo, Piracicaba, 2010.

CHANDER, G.; MARKHAM, B. Revised Landsat-5 TM Radiometric Calibration Procedures ans Postcalibration Dynamic Ranges. IEEE Transactions on Geoscience and Remote Sensing, v. 41. n. 11, p. 2674-2677, 2003.

COMPANHIA DE GESTÃO DOS RECURSOS HÍDRICOS. Bacia hidrográfica. 2017. Disponível em: <https://www. cogerh.com.br/bacias-hidrografica.html>. Acesso em: 15 out. 2017.

CUNHA, John E. B. L. et al. Dinâmica da cobertura da terra na região semiárida utilizando sensoriamento remoto. 2012. Disponível em: <http://www.hidro.ufcg.edu.br/twiki/pub/GeoTermal0/Publica??esgeotermal/ Dinmicadacoberturadaterranaregiosemiridautilizandosensoriamentoremoto.pdf $>$. Acesso em: 11 abr. 2018.

CRISPIM, A. B. Sistemas ambientais e vulnerabilidades ao uso da terra no vale do rio Pacoti - CE: subsídios ao ordenamento territorial. 2011. 201 f. Dissertação (Mestrado) - Curso de Geografia, Centro de Ciências e Tecnologia, Universidade Estadual do Ceará, Fortaleza, 2011. Disponível em: <http://www.uece.br/mag/dmdocuments/andrea dissertacao.pdf $>$. Acesso em: 15 nov. 2017.

DANTAS, Fabiane R. da Cunha; NASCIMENTO, Francisco das C. A. do; BRAGA, Célia C. Análise comparativa do SAVI sobre regiões da caatinga brasileira obtido por dados remotos. 2012. Disponível em: <http://www.gvaa.com. br/revista/index.php/RVADS/article/view/1190/1459>. Acesso em: 30 abr. 2018. 
Análise do albedo da superfície e de índices de vegetação por sensoriamento remoto na bacia hidrográfica do Rio Pacoti/CE

DANTAS, Maria Jorgiana F. Evapotranspiração na sub-bacia do Riacho Jardim - CE, por sensoriamento remoto. 2013. 120 f. Tese (Doutorado) - Curso de Agronomia, Ciências Agronômicas, Universidade Estadual Paulista Júlio de Mesquita Filho, Botucatu, 2013.

DANTAS, M. J. F. et al. Variabilidade espacial do NDVI no Município de Pacoti/CE. 2017. Disponível em: < https:// drive.google.com/file/d/0B9cQbhL617PHMVpnaXo0N19mcUk/view>. Acesso em: 14 out. 2017.

DEMARCHI, Julio Cesar; PIROLI, Edson Luís; ZIMBACK, Célia Regina L. Análise temporal do uso do solo e comparação entre os índices de vegetação NDVI e SAVI no unicípio de Santa Cruz do Rio Pardo -SP usando imagens LANDSAT-5. 2011. Disponível em: $<$ https://revistas.ufpr.br/raega/article/viewFile/17416/14028>. Acesso em: 30 abr. 2018.

FUNDAÇÃO CEARENSE DE METEOROLOGIA E RECURSOS HÍDRICOS. Calendário das Chuvas no Estado do Ceará. 2018. Disponível em: <http://www.funceme.br/app/calendario/produto/bacias/media/mensal $>$. Acesso em: 11 abr. 2018.

GIONGO, Pedro R.; VETTORAZZI, Carlos A. Albedo da superfície por meio de imagens TM-Landsat 5 e modelo numérico do terreno. 2014. Disponível em: <http://web.b.ebscohost.com/ehost/pdfviewer/ pdfviewer?vid=6\&sid=f748be85-d43d-4f0b-b55a-22a6454052dd@sessionmgr101>. Acesso em: 11 abr. 2018.

GOMES, Helio Fábio B. Balanços de radiação e energia em áreas de cultivo de cana-de açúcar e cerrado no Estado de São Paulo mediante imagens orbitais. 2009. 124 f. Tese (Doutorado em Meteorologia) - Centro de Tecnologia e Recursos Naturais, Universidade Federal de Campina Grande, Campina Grande, 2009.

HUETE, A. R. A soil-adjusted vegetation index. Remote Sensing of Environment, New York, USA, v.25, n. 3, p. 295-309, 1988. Disponível em: <https://www.sciencedirect.com/science/article/pii/003442578890106X> . Acesso em: 14 out. 2017.IDEIÃO, S. M. A. Imagens multiespectrais e aplicações em recursos hídricos: temperatura da superfície e balanços de radiação e energia. 2009. 156 f. Dissertação (Mestrado em Engenharia Civil) - Universidade Federal de Campina Grande, Campina Grande, 2009. Disponível em: <http://www.hidro.ufcg.edu.br/dissertacoes/ Ideiao_Agosto_2009.pdf >.Acesso em: 14 out. 2017.

INSTITUTO DE PESQUISA E ESTRATÉGIA ECONÔMICA DO CEARÁ. Perfil Básico Municipal: Pacoti, 2016. Disponível em: <http://www.ipece.ce.gov.br/perfil_basico_municipal/2016/Pacoti.pdf >. Acesso em: 24 set. 2017.

LIMA, Mirelle Taina V. et al. NDVI como ferramenta no auxílio à localização de poços na região Metropolitana do Cariri. 2017. Disponível em: <https://drive.google.com/file/d/0B9cQbhL617PHMWVGU01STEwxTm8/view>. Acesso em: 11 abr. 2018.

MAGALHÃES, Ivo Augusto L.; CARVALHO JUNIOR, Osmar A. de; SANTOS, Alexandre Rosa dos. Análise comparativa entre técnicas de sensoriamento remoto para mensuração da vegetação urbana no Município de Alegre, ES. 2017. Disponível em: <http://rnp-primo.hosted.exlibrisgroup.com/primo_library/libweb/action/display.do ?tabs $=$ viewOnlineTab\&gathStatTab=true $\& \mathrm{ct}=$ display $\& \mathrm{fn}=$ search $\& \mathrm{doc}=\mathrm{TN}$ _doaj_soai_doaj_org_article_8bca0b16cc1 d41feaf0d6e1914136fa7\&indx=1\&recIds=TN_doaj_soai_doaj_org_article_8bca0b16cc1d41feaf0d6e1914136fa7\&rec Idxs $=0 \&$ elementId $=0 \&$ renderMode $=$ poppedOut \&displayMode $=$ full $\&$ frbrVersion $=\&$ frbg $=\& \& d s c n t=0 \&$ scp. scps $=$ scop e:(“CAPES”),EbscoLocalCAPES,primo_central_multiple_fe\&mode=Basic\&vid=CAPES_V1\&srt=rank\&tab=default_ tab\&vl(freeText0)=índice de vegetação savi\&dum=true\&dstmp=1525884106826>. Acesso em: 30 abr. 2018.

MENESES, P. R.; ALMEIDA, T. de. Introdução ao processamento de imagens de sensoriamento remoto. Embrapa Cerrados-Livros técnicos (INFOTECA-E). 2012. Disponível em: $<$ https://s3.amazonaws.com/academia.edu. documents/33333156/MENESES_ALMEIDA_2012_INTRO_AO_PROCESSAMENTO_DE_IMAGEM.pdf?AWS AccessKeyId=AKIAIWOWYYGZ2Y 53 UL3A\&Expires $=1508019455 \&$ Signature $=2 \mathrm{nFgvL} \overline{\mathrm{kn}} 1 \mathrm{yBpXkxZ} \% 2 \mathrm{~F} 4 \mathrm{FD} 7 \mathrm{eQ}$ FHzA\%3D\&response-content-disposition=inline\%3B\%20filename\%3DMENESES_and_ALMEIDA_2012_INTRO_ AO_PROCES.pdf $>$. Acesso em: 14 out 2017.

NASCIMENTO, Francisco das Chagas A. do; ARAÚJO, Fabiane Regina da C. Dantas. Estudo comparativo entre o IVDN e a precipitação na região Oeste Potiguar. 2014. Disponível em: $<$ http://www.gvaa.com.br/revista/index.php/ RVADS/article/view/2256/2447>. Acesso em: 12 abr. 2018.

NICÁCIO, R. M. Evapotranspiração real e umidade do solo usando dados de sensores orbitais e a metodologia SEBAL na bacia do Rio São Francisco. 2008. 320 f. Tese (Doutorado em Engenharia Civil) - Universidade Federal do Rio de Janeiro, Rio de Janeiro, 2008. 
QUEIROZ, P. H. B. de. Planejamento ambiental aplicado a um setor do médio curso da bacia hidrográfica do Rio Pacoti-CE. Mercator Revista de Geografia da UFC, Fortaleza, v. 9, n. 19, p. 192, 2010. Disponível em: <http://www. repositorio.ufc.br/handle/riufc/9024> Acesso em: 29 out. 2017.

SILVA, B. B. da; LOPES, G. M.; AZEVEDO, P.V. de. "Determinação do albedo de áreas irrigadas com base em imagen", Revista Brasileira de Agrometeorologia, Santa Maria, v. 13, n. 2, p. 11-21, 2005.

TASUMI, M. Progress in operational estimation of regional evapotranspiration using satellite imagery. $\mathrm{PhD}$ thesis. Dept. Biological and Agricultural Engineering, University of Idaho, Idaho, 2003.

TUCCI, C. E. M; MENDES, C. A. Curso de avaliação ambiental integrada de bacia hidrográfica. Brasília:

Ministério do Meio Ambiente, 2006. Disponível em: <http://www.mma.gov.br/estruturas/sqa_pnla/_arquivos/sqa_3. pdf>. Acesso em: 12 nov. 2017.

ZANZARINI, Fabricio V. et al. Correlação espacial do índice de vegetação (NDVI) de imagem Landsat/

ETM+ com atributos do solo. 2013. Disponível em: $<$ http://www.scielo.br/scielo.php?script=sci_arttext\&pid $=$ S1415-43662013000600006>. Acesso em: 12 abr. 2018.

\section{Sobre os autores}

\section{José Jeová Ferreira Júnior}

Engenheiro Ambiental e Sanitarista, Universidade de Fortaleza - Unifor

Tem experiência na área de Ciências Ambientais.

\section{Maria Jorgiana Ferreira Dantas}

Mestre da Universidade de Fortaleza- Unifor. Possui graduação em Recursos Hídricos/Saneamento Ambiental pela Faculdade de Tecnologia Centec-Cariri (2008), mestrado em Engenharia Agrícola pela Universidade Federal do Ceará (2010) e doutorado em Agronomia (Energia na Agricultura) pela Universidade Estadual Paulista Júlio de Mesquita Filho, Faculdade de Ciências Agronômicas (2013). Bolsista de doutorado sanduíche pela CAPES na Universidad de Valêncial Espanha. Tem experiência na área de Saneamento Ambiental, Engenharia Agrícola, Sensoriamento Remoto e Expressão Gráfica com ênfase em Recursos Hídricos e Geoprocessamento Ambiental. 